\title{
Safety Effects of Horizontal Curve Design and Lane and Shoulder Width on Single Motorcycle Accidents in Norway
}

\author{
Sara Kvasnes, ${ }^{1}$ Petr Pokorny $\mathbb{D}^{2},{ }^{2}$ Jan Kristian Jensen, ${ }^{3}$ and Kelly Pitera $\mathbb{D}^{1}$ \\ ${ }^{1}$ Department of Civil and Environmental Engineering, Norwegian University of Science and Technology, \\ 7030 Trondheim, Norway \\ ${ }^{2}$ Institute of Transport Economics, 0349 Oslo, Norway \\ ${ }^{3}$ Norwegian Public Roads Administration, 7030 Trondheim, Norway \\ Correspondence should be addressed to Kelly Pitera; kelly.pitera@ntnu.no
}

Received 30 October 2020; Revised 11 March 2021; Accepted 18 March 2021; Published 22 April 2021

Academic Editor: Filomena Mauriello

Copyright (C) 2021 Sara Kvasnes et al. This is an open access article distributed under the Creative Commons Attribution License, which permits unrestricted use, distribution, and reproduction in any medium, provided the original work is properly cited.

\begin{abstract}
Factors related to the road infrastructure contribute to the occurrence of motorcycle accidents. This study investigates how design parameters of the existing rural two-lane road network in Norway influence the occurrence of single motorcycle accidents. The design elements considered in this study are horizontal curvature (curve type, degree of curvature, and adjacent curve requirements) and lane and shoulder widths. A matched case-control study design was applied to investigate the safety effects of these elements. Cases were defined as segments experiencing at least one single motorcycle accident during the study period from 2013 to 2017, while controls were defined as segments not experiencing an accident in the same period. In order to identify the segments, a GIS analysis was performed on data collected from the National Road Database (NVDB). In case-control studies, matching allows us to control for confounding variables. AADT and speed limit were used as matching variables in this study. A matching ratio of 4:1 (i.e., four controls per case) was used, resulting in 752 controls being matched to 188 cases. The results indicate horizontal alignment to have a more significant effect on single motorcycle accidents compared to lane and shoulder widths. Segments with several adjacent reverse curves, with high curvature $(R<200 \mathrm{~m})$, have high odds for an accident. Further, if the requirements for adjacent curves are not fulfilled (i.e., considerable variation in adjacent curve radii), the odds increase even more. While the results are not statistically significant, trends seen indicate that wider lanes were associated with increased odds for an accident, while wider shoulders were associated with decreased odds. In comparison with a similar study considering passenger vehicles, the results of this study also indicate that horizontal alignment has a greater effect on single motorcycle accidents than on passenger vehicle accidents.
\end{abstract}

\section{Introduction}

Vision Zero, a national level goal of reaching zero killed or severely injured in traffic, has been a guiding principle in traffic safety in Norway for several decades [1], resulting in a large reduction of the number of severely injured and killed people in traffic accidents. This reduction is primarily a result of the reduced number of severely injured and killed car occupants, which decreased by $58 \%$ and $62 \%$, respectively, in the period from 2001 to 2019 , compared to $14 \%$ and $53 \%$ for motorcyclists [2]. Risk levels have decreased over time for all road user groups in Norway, including motorcycles [3]; however, the number of accident victims is still far from the Vision Zero target. In 2019, 16 motorcycle riders died, while 118 were severely injured [2].

The risks associated with motorcycle driving have been subject to extensive traffic safety research. As motorcyclists are more vulnerable and less protected than car occupants, the risk of fatality or severe injury when involved in an accident is several times higher for motorcycle riders than for car occupants [4]. The majority of the researches have been focused on human-related risk factors such as alcohol abuse $[5,6]$, the extent of injury $[7,8]$, and other features like age, gender, and the use of safety equipment [9-11]. While researches have considered risk factors related to motorcycle accidents and road geometry [12-16], research on single- 
vehicle accidents on rural two-lane roads is limited. A recent analysis of fatal motorcycle accidents in Norway showed that a considerable part (40\%) of these accidents only included a single vehicle. It also showed that factors related to the road, such as road geometry (most often curve geometry), were contributory factors in every fourth fatal motorcycle accident [17].

In Norway, the requirements for road geometry and design are provided in standards published by the Norwegian Public Roads Administration (NPRA). These standards are revised regularly, and design parameters are frequently changed. However, these changes are typically not based on safety research or at least documented as such [18].

The aim of this study is to investigate the relationship between single motorcycle accidents and road geometry. The elements within road geometry that will be investigated are horizontal curvature, lane width, and shoulder width. These elements affect the motorcyclists' behavior, as the distance to an upcoming horizontal curve has a significant impact on the change of throttle and the brake force applied by the motorcyclist [19], and the lane width and adjacent roadside affect overtaking speed and lateral positioning [20].

Horizontal curves are an essential element of road geometry, which is why many studies have examined their safety effects. Elvik [21] investigated the transferability of accident modification functions for horizontal curves by comparing models developed in several different countries. The models included in the study reported a decrease in accident rate with an increasing radius. Though a small curve radius is associated with increased risks for an accident, more recently Elvik [22] found that small adjacent curves are associated with a lower accident rate compared to larger adjacent curves. Elvik [22] also found that the presence of several curves with shorter straight distances (i.e., $50 \mathrm{~m}$ ) in between each curve results in lower accident rates. While some literature on curve radius shows increased risk of an accident in sharp curves, the presence of several sharp curves can have a positive effect, as it could encourage lower speeds and more careful driving.

Only a few studies consider motorcycles and horizontal curvature exclusively, specifically for single-vehicle accidents on two-lane roads. One study that did so was conducted by Schneider et al. [23]. The study estimated the accident frequency with the use of a negative binomial regression model and 225 police-reported single motorcycle accidents in Ohio. The results showed that both radius and curve length had a significant impact on the accident frequency, with sharper and longer curves increasing the motorcyclists' risk. The study also found that accidents occur most frequently in curves and that the frequency decreases as the motorcyclist travels further away from the curve. These findings might be explained by the fact that sharp curves are more demanding for riders and can attract more riskseeking riders compared to straight road sections.

Another study, again using a negative binomial regression model, investigated the relationship between single motorcycle accidents and horizontal geometry [24]. The data were collected on rural two-lane road segments located in Florida and involved 439 motorcycle accidents over 11 years.
The results indicate the same effects as the study by Schneider et al. [23], which showed that sharper and longer curves induce an increased accident frequency. The study also investigated the effects of different curve types (i.e., single curves, compound curves, and reverse curves) and found that the accident frequency is reduced when a reverse curve is present. A reverse curve was defined as a curve consisting of two jointed curves in opposite directions. The same accident dataset was included in a more recent study by Xin et al. [25], which aimed to estimate the accident modification factors (AMFs) for horizontal curve features on single motorcycle accidents using a case-control study design. The findings were consistent with the previous two studies. The AMF was highest for sharp nonreverse curves.

Similar to horizontal alignment, a large number of studies on the safety effects of the traffic lane and shoulder widths have been conducted worldwide, but the specific research on motorcycle accidents remains limited. In general, the safety literature on lane and shoulder widths shows the variability of results. According to the Handbook of Road Safety Measures [26], lane width seems to be related to accidents; however, the relationship depends on many other factors and can be either positive or negative. Gitelman et al. [27] used a negative binomial regression model and a casecontrol study to investigate the safety effects of traffic lane widths. The results provided by the two methods were consistent and showed that the number of severe accidents was less when traffic lanes were narrow. However, these results are inconsistent with the results from a study by Gross and Donnell [28] who also applied a case-control study design, along with a cross-section design. The results showed an increased risk for narrow lanes, which also is supported in a study by Gross and Jovanis [29]. Wider traffic lanes provide extra recovery space, which can help reduce the number of accidents. However, they might also encourage higher speed levels.

Regarding shoulder widths, studies report very different findings depending on local context, data quality, different sample sizes, and local specifics regarding the reporting of the accidents, among other factors. For example, one study from Israel reported a nonmonotonous relationship between shoulder width and accident risk, with increasing risk for widths up to $2.2 \mathrm{~m}$ [27], while several American studies reported a monotonous link with decreased risk for wider shoulders $[28,29]$. Similar to lane width, some of these results can be explained by the extra recovery space provided by the shoulders and the possibility to conduct an emergency stop without interfering with traffic [26]. On the other hand, wider shoulders might also encourage higher speed levels, which again could increase risk. When considering traffic lane and shoulder width simultaneously, a study by Gross et al. [30] found no clear trends on whether it was beneficial to increase the traffic lane width or the shoulder width for fixed total width. These results were inconsistent with a previous study by Zegeer et al. [31], which found that it to be beneficial to increase the traffic lane width.

There was only one study on lane and shoulder widths that focused explicitly on single motorcycles accidents on rural two-lane roads. Schneider et al. [21] identified $6 \mathrm{ft}$ 
$(1.8 \mathrm{~m})$ to be the critical shoulder width regarding single motorcycle accidents. Based on a negative binomial regression model, the accident frequency is expected to increase by more than $50 \%$ if the shoulder width is less than $1.8 \mathrm{~m}$.

This study described within this paper is also linked with a previous matched case-control study by Pokorny et al. [32] that investigated the safety effects of lane and shoulder widths on single and head-on motor vehicle accidents on rural two-lane roads in Norway. In order to compare the findings, the same methodology and dataset have been applied. The results of this study increase the knowledge of risk factors related to single motorcycle accidents in Norway, which, if considered, could increase the safety level of future road facilities.

\section{Method}

Observational studies (e.g., before-after studies and crosssection studies) are commonly used to estimate the safety effects of geometrical road features. Before-after studies are usually preferred over cross-section studies but can be timeconsuming as collecting data can take several years, and it can be challenging to find a sufficient sample size. Therefore, some features are better examined by a cross-section study (e.g., horizontal curves). However, the challenge with crosssection studies is that it can be difficult to identify sections with similar features, besides the feature of interest to use within the analysis. Unlike cross-section studies, case-control studies can examine the safety effect of several features simultaneously (i.e., horizontal curves and traffic lane widths). The case-control study design also provides the ability to control for confounding variables when a matching scheme is applied [33]. Based on this, the case-control study design was considered suitable for the current study.

The case-control study design was initially used within epidemiology but has in more recent times also been used within traffic safety research [28]. The purpose of the casecontrol study design is to investigate the effect of risk factors by comparing a group of cases and controls. Case-control studies should not be mistaken with cross-section studies. Unlike cross-section studies, case-control studies select sites based on the outcome (accident or no accident) rather than the presence of a specific feature [33]. The approach of this case-control study is separated into three main steps, illustrated in Figure 1.

One of the main challenges with the case-control study design is defining cases and controls. The results produced can be unclear if the definition of cases and controls is not specific. It is also essential that the cases and controls are representative of the sites of interest [33]. For this study, a case is defined as a rural two-lane road segment experiencing at least one single motorcycle accident within the study period, 2013-2017. Control is defined as a rural two-lane road segment which has not experienced an accident during the same period.

The case-control study design should recognize differences between segments with multiple accidents and single accidents. If this is not taken into account, the safety effect can be underestimated [34]. In this study, six segments experienced multiple accidents. These were defined as multiple cases (i.e., one segment experiencing two accidents is separated into two cases), making the features associated with multiple accidents more frequent among the cases.

Applying a matching scheme allows controlling for confounding variables. Controls are matched to each case based on the same value of the confounding variables. The confounder must be associated with both the risk factors (horizontal curvature and lane and shoulder width) and the outcome (single motorcycle accident). If this is not the case, one can experience a biased result due to overmatching [35]. The traffic volume (AADT) and the speed limit were identified as confounding variables in the current study. They are both related to road geometry as the design classes in Norway are adapted to speed limit and AADT, among other factors (i.e., dimensioning vehicle type and topography) [30]. The speed limit is used to determine the minimum curve radius, while wider roads usually are associated with higher AADT [36, 37]. Although AADT does not indicate the proportion of motorcyclists, it has been proven to impact the frequency of single motorcycle accidents ( $1 \%$ increase in AADT results in $0.43 \%$ increased frequency of single motorcycle accidents) [23]. Speed has also been proven to affect the risk of a motorcycle accident in studies by Vlahogianni et al. [11] and Jevtić et al. [38]. In this study, the speed limit is considered as a surrogate measure of speed.

The power of a matched case-control study increases when the control-to-case ratio increases (i.e., several controls are matched to each case). However, the power stagnates when the ratio exceeds four [28]. Due to a large number of controls available in this study, a $4: 1$ ratio was applied, with four controls randomly matched to each case by using the random function in the Python programming language.

The case-control method cannot be used to determine the expected accident frequency. Instead, it is used to find an approximation of the relative risk presented as an odds ratio. The odds ratio indicates the increased or decreased risk associated with a treatment [32]. It is expressed as the change in relative risk compared to a baseline. For binary risk factors (absence or presence), the baseline is usually considered as the risk factor being absent. For categorical risk factors, any category can be considered as the baseline [26]. In this study, the most frequent parameter for each category was considered as the baseline.

Conditional logistic regression is a commonly used technique to estimate the odds ratio in case-control studies $[25,27,39]$. The probability of a single motorcycle accident is given by equation (1) and is further used to calculate the odds ratio, as cited by $[25,30,34]$ :

$$
\operatorname{Pr}\left(y_{i j}=1\right)=\frac{1}{1+\exp \left[-\left(\alpha_{i}+\sum_{k} \beta_{k} x_{i j k}\right)\right]},
$$

where $y_{i j}$ is the outcome in the $j^{\text {th }}$ segment in the $i^{\text {th }}$ stratum $\left(1=\right.$ case and $0=$ control). $\alpha_{i}$ is the effect of matching variables for each matched stratum (sets on 4 controls and 1 case). $\beta_{k}$ is the estimated coefficients for unmatched 


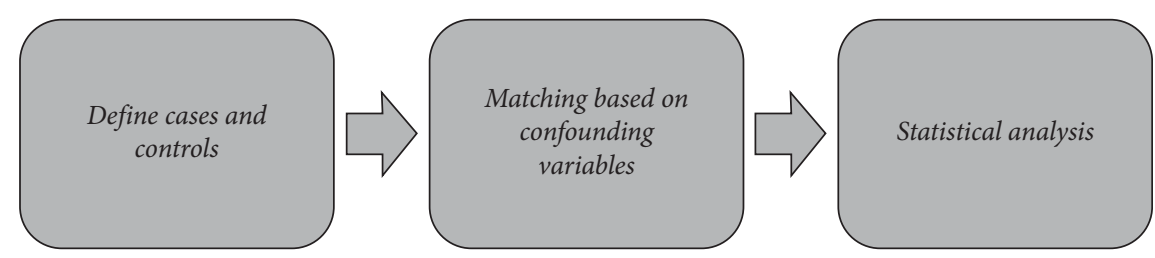

Figure 1: The three main steps of a case-control study design.

variables. $x_{i j k}$ is the $k^{\text {th }}$ unmatched covariate in the $j^{\text {th }}$ segment in the $i^{\text {th }}$ stratum.

\section{Segmented Network}

The data on road design parameters, traffic operation, and accidents used in the study were collected from the Norwegian National Road Database (NVDB) for the study period 2013-2017. NVDB is provided by the NPRA. The study focuses on undivided two-lane rural roads (classified as European, Regional, or District roads according to the Norwegian classification, ERF roads). Roads with low ( $\leq$ $50 \mathrm{~km} / \mathrm{h})$ and high $(\geq 90 \mathrm{~km} / \mathrm{h})$ speed limits were excluded from the network. Additionally, all tunnels and bridges over $20 \mathrm{~m}$ were excluded, along with intersections and all adjacent road sections within a radius of $100 \mathrm{~m}$. Intersections were defined as intersections between ERF roads and roads with higher functional classes (thereby excluding forest, agriculture, and other low-class roads). The segmented network was initially created by Pokorny et al. [32] and was reused, with slight modifications, for the current study. The modifications included adding a parameter on whether the adjacent curves met the Norwegian standard or not, to provide more detailed results related to horizontal alignment. In addition, the data was handled by different software in the two studies, which may also have caused some differences in the dataset. Despite these differences, the results are considered comparable as the modification does not affect the way the road is segmented, only the categorization of the segments. Also, the way the data are structured within this study allows for the exclusion of the parameter on adjacent curves when comparing the results of the current study to the results of Pokorny et al. [32]. For more details on the segmentation process, consult the referenced paper by Pokorny et al. [32].

A description of the final dataset, consisting of 58,815 segments, is provided in Table 1.

For segments with a variation in lane and shoulder width (but not enough variation to create a new segment), a weighted average was used as an estimate. The coefficient of variation $(\mathrm{CV})$ was calculated to evaluate the precision of the weighted average estimate. $99.9 \%$ of the segments showed a sufficient $\mathrm{CV}(\mathrm{CV}<0.5)$ [27].

The horizontal alignment was treated slightly differently from the study by Pokorny et al. [32], as it was relevant to include adjacent curve requirements in the current study. The segments were categorized according to curve type, degree of curvature, and adjacent curves, all based on the radius information. First, the segments were divided into four classes: straight $(R=0$ or $|\mathrm{R}|>1750 \mathrm{~m}$, as suggested by
Norwegian design standards [36]), single curve, multiple curves in the same direction, and multiple curves in opposite directions. Furthermore, the curved segments were divided into two categories determining whether the curvature was high $(R<200 \mathrm{~m})$ or low $(R>200 \mathrm{~m})$. The value of $200 \mathrm{~m}$ was used as a limit value, as the relative accident rate seems to be increasing drastically for radii below $200 \mathrm{~m}$ [21]. For multiple curved segments, a weighted average of the radiuses $R_{\mathrm{w}}$ (using absolute values) was calculated to determine the high or low classification.

Lastly, the multiple curved segments were divided into two categories determining whether the requirements for adjacent curves were fulfilled (OK) or not (NOT OK). These requirements are given by the Norwegian standard for geometric road design, Handbook V120 Premises of geometric road design [37]. The purpose is to provide an even and consistent curvature. For curve radii less than or equal to $300 \mathrm{~m}$, there are requirements for the minimum and maximum radii adjacent to the curve. The same criterion was applied in this study. As can be seen in Table 2, although this is a standard requirement within Norwegian road design, the existing network contains a significant share of segments where the requirements are not fulfilled.

\section{Accidents}

The accident data were retrieved from NVDB, where an accident is registered if it has led to personal injury or great material damage [40]. In total, 188 single motorcycle accidents from the period of 2013-2017 were assigned to the segmented network based on their GPS data. Because of the relatively low number of accidents, all five years were analyzed together. According to the descriptive statistics (see Table 3), most of the accidents occurred in curves (most frequently in left-hand curves) and most of the single motorcycle accidents resulted in slight injury.

\section{Statistical Model}

The analysis was conducted using the statistical software SPSS. The COXREG function was used as a substitute for conditional logistic regression, as the results produced by the COXREG are equal to the ones produced by a conditional logistic regression. The covariates included in the statistical model were horizontal alignment, traffic lane width, shoulder width, region, road type, and the percentage of long vehicles $(>5.6 \mathrm{~m})$. The three parameters on horizontal alignment were merged together, resulting in 11 different combinations describing the horizontal alignment of each segment (as seen in Table 4). 
TABLE 1: Descriptive statistics of the final dataset, 58815 segments.

\begin{tabular}{|c|c|c|c|c|c|}
\hline \multicolumn{2}{|c|}{ Parameter } & Number of segments & $\%$ of segments & $\%$ of total length & $\%$ of accidents \\
\hline \multirow{8}{*}{ Lane width } & $1.5-1.75 \mathrm{~m}$ & 2347 & 3.99 & 3.94 & 2.13 \\
\hline & $1.76-2.0 \mathrm{~m}$ & 3402 & 5.78 & 5.81 & 2.13 \\
\hline & $2.01-2.25 \mathrm{~m}$ & 5284 & 8.98 & 8.92 & 3.19 \\
\hline & $2.26-2.5 \mathrm{~m}$ & 6351 & 10.80 & 10.92 & 6.91 \\
\hline & $2.51-2.75 \mathrm{~m}$ & 9075 & 15.43 & 15.44 & 11.17 \\
\hline & $2.76-3.0 \mathrm{~m}$ & 15,558 & 26.45 & 26.50 & 33.51 \\
\hline & $3.01-3.25 \mathrm{~m}$ & 12,183 & 20.71 & 20.67 & 27.13 \\
\hline & $3.26-3.5 \mathrm{~m}$ & 4615 & 7.85 & 7.81 & 13.83 \\
\hline \multirow{5}{*}{ Shoulder width } & $0-0.25 \mathrm{~m}$ & 15,611 & 26.54 & 26.94 & 32.45 \\
\hline & $0.26-0.5 \mathrm{~m}$ & 25,037 & 42.57 & 21.44 & 45.21 \\
\hline & $0.51-0.75 \mathrm{~m}$ & 12,644 & 21.50 & 42.49 & 16.49 \\
\hline & $0.76-1.0 \mathrm{~m}$ & 3549 & 6.03 & 5.91 & 4.26 \\
\hline & $>1 \mathrm{~m}$ & 1974 & 3.36 & 3.22 & 1.60 \\
\hline \multirow{5}{*}{ Region } & East & 20,115 & 34.20 & 33.71 & 45.21 \\
\hline & Middle & 9259 & 15.74 & 15.38 & 8.51 \\
\hline & North & 16,426 & 27.93 & 28.93 & 14.89 \\
\hline & South & 4576 & 7.78 & 7.75 & 10.64 \\
\hline & West & 8439 & 14.35 & 14.23 & 20.74 \\
\hline \multirow{3}{*}{ Road type } & European & 7164 & 12.18 & 12.52 & 14.36 \\
\hline & County & 47,123 & 80.12 & 79.67 & 76.60 \\
\hline & District & 4528 & 7.70 & 7.81 & 9.04 \\
\hline \multirow{6}{*}{ AADT } & $<500$ & 25,514 & 43.38 & 43.73 & 23.40 \\
\hline & $501-1500$ & 18,851 & 32.05 & 31.85 & 35.64 \\
\hline & $1501-4000$ & 11,319 & 19.25 & 19.23 & 31.38 \\
\hline & $4001-6000$ & 1914 & 3.25 & 3.22 & 4.79 \\
\hline & $6001-8000$ & 601 & 1.02 & 0.99 & 1.06 \\
\hline & $>8000$ & 616 & 1.05 & 0.98 & 3.72 \\
\hline \multirow{3}{*}{$\%$ of long vehicles } & $<8 \%$ & 11,172 & 19.00 & 18.61 & 16.49 \\
\hline & $8-12 \%$ & 29,599 & 50.33 & 50.06 & 51.60 \\
\hline & $>12 \%$ & 18,044 & 30.68 & 31.34 & 31.91 \\
\hline \multirow{3}{*}{ Speed limit } & $60 \mathrm{~km} / \mathrm{h}$ & 8934 & 15.19 & 14.58 & 13.83 \\
\hline & $70 \mathrm{~km} / \mathrm{h}$ & 2611 & 4.44 & 4.33 & 4.26 \\
\hline & $80 \mathrm{~km} / \mathrm{h}$ & 47,270 & 80.37 & 81.09 & 81.91 \\
\hline
\end{tabular}

TABle 2: Descriptive statistics on horizontal alignment.

\begin{tabular}{|c|c|c|c|c|}
\hline \multicolumn{2}{|c|}{ Horizontal alignment categories } & Number of segments & $\%$ of segments & $\%$ of total length \\
\hline \multirow{4}{*}{ Curve type } & Multiple curves in opposite direction & 17,921 & 30.47 & 34.82 \\
\hline & Multiple curves in the same direction & 6604 & 11.23 & 10.33 \\
\hline & Single & 4925 & 8.37 & 6.18 \\
\hline & Straight & 29,365 & 49.93 & 48.67 \\
\hline \multirow{3}{*}{ Degree of curvature } & High $(\mathrm{R}<200 \mathrm{~m})$ & 4641 & 7.89 & 7.22 \\
\hline & Low $(\mathrm{R}>200 \mathrm{~m})$ & 24,809 & 42.18 & 44.11 \\
\hline & Straight & 29,365 & 49.93 & 48.67 \\
\hline \multirow{4}{*}{ Neighbor curves } & NOT OK & 13,252 & 22.53 & 27.91 \\
\hline & $\mathrm{OK}$ & 11,273 & 19.17 & 17.24 \\
\hline & Single & 4925 & 8.37 & 6.18 \\
\hline & Straight & 29,365 & 49.93 & 48.67 \\
\hline
\end{tabular}

\section{Results}

The results of the statistical analysis are presented in Table 5, where the significance levels, odds ratio, and $95 \%$ confidence intervals are included.

Almost all of the results on lane and shoulder width were not statistically significant (only the result for width $1.76-2.00 \mathrm{~m}$ ), and the confidence intervals are large. However, the results appear to be presenting some trends. For traffic lane widths
(Figure 2(a)), the trend appears to be an increased odds ratio for wider lanes. The opposite trend appears for shoulder widths (Figure 2(b)), where wider shoulders are associated with lower odds ratio.

The results on horizontal curvature were more significant compared to the results on lane and shoulder width. Yet, some of the confidence intervals are large, as seen in Figure 3. The highest odds ratio is associated with multiple curved segments, with high curvature, not fulfilling the requirements for adjacent curves (i.e., 
TABLE 3: Descriptive statistics on accidents.

\begin{tabular}{cccc}
\hline & Accident categories & number of accidents & \% of accidents \\
\hline & Fatality & 17 & 9.04 \\
Degree of injury & Severe injury (severe + very severe) & 41 & 21.81 \\
& Slight injury & 127 & 67.55 \\
& No injury/not registered & 3 & 1.60 \\
\hline & Straight & 40 & 21.28 \\
Road geometry & Left-hand curves & 86 & 45.74 \\
& Right-hand curves & 37 & 19.68 \\
& Unknown & 25 & 13.30 \\
\hline
\end{tabular}

TABLE 4: Combinations describing the horizontal alignment in the statistical model.

\begin{tabular}{|c|c|c|c|c|}
\hline Curve type & Degree of curvature & Adjacent curve requirements & Number of segments & Percentage of segments \\
\hline Straight & & & 430 & $45.74 \%$ \\
\hline Single curve & High & & 67 & $7.13 \%$ \\
\hline Single curve & Low & & 6 & $0.64 \%$ \\
\hline Multiple curves in the same direction & High & $\mathrm{OK}$ & 15 & $1.60 \%$ \\
\hline Multiple curves in the same direction & High & NOT OK & 1 & $0.11 \%$ \\
\hline Multiple curves in the same direction & Low & $\mathrm{OK}$ & 40 & $4.26 \%$ \\
\hline Multiple curves in the same direction & Low & NOT OK & 58 & $6.17 \%$ \\
\hline Multiple curves in opposite directions & High & $\mathrm{OK}$ & 44 & $4.68 \%$ \\
\hline Multiple curves in opposite directions & High & NOT OK & 29 & $3.09 \%$ \\
\hline Multiple curves in opposite directions & Low & $\mathrm{OK}$ & 95 & $10.11 \%$ \\
\hline Multiple curves in opposite directions & Low & NOT OK & 155 & $16.49 \%$ \\
\hline
\end{tabular}

TABLE 5: Results of the statistical analysis. Significant $(p<0.05)$ results presented in bold font.

\begin{tabular}{|c|c|c|c|c|c|}
\hline \multirow[t]{2}{*}{ Parameters } & & \multirow[t]{2}{*}{ Significance } & \multirow[t]{2}{*}{ Odds ratio } & \multicolumn{2}{|c|}{$\begin{array}{l}95.0 \% \text { CI for the } \\
\text { odds ratio }\end{array}$} \\
\hline & & & & Lower & Upper \\
\hline \multirow{8}{*}{ Lane width } & $1.5-1.75 \mathrm{~m}$ & 0.383 & 0.518 & 0.118 & 2.271 \\
\hline & $1.76-2.0 \mathrm{~m}$ & 0.015 & 0.208 & 0.059 & 0.738 \\
\hline & $2.01-2.25 \mathrm{~m}$ & 0.196 & 0.476 & 0.155 & 1.467 \\
\hline & $2.26-2.5 \mathrm{~m}$ & 0.592 & 0.806 & 0.366 & 1.776 \\
\hline & $2.51-2.75 \mathrm{~m}$ & 0.272 & 0.703 & 0.375 & 1.318 \\
\hline & $2.76-3.0 \mathrm{~m}$ & 0.383 & 1 & 1 & 1 \\
\hline & $3.01-3.25 \mathrm{~m}$ & 0.547 & 0.859 & 0.525 & 1.407 \\
\hline & $3.26-3.5 \mathrm{~m}$ & 0.973 & 0.989 & 0.520 & 1.880 \\
\hline \multirow{5}{*}{ Shoulder width } & $0-0.25 \mathrm{~m}$ & 0.881 & 1 & 1 & 1 \\
\hline & $0.26-0.5 \mathrm{~m}$ & 0.836 & 1.047 & 0.680 & 1.611 \\
\hline & $0.51-0.75 \mathrm{~m}$ & 0.525 & 0.837 & 0.483 & 1.450 \\
\hline & $0.76-1.0 \mathrm{~m}$ & 0.702 & 0.817 & 0.290 & 2.302 \\
\hline & $>1 \mathrm{~m}$ & 0.514 & 0.622 & 0.150 & 2.586 \\
\hline \multirow{5}{*}{ Region } & East & 0.343 & 1 & 1 & 1 \\
\hline & Middle & 0.304 & 0.691 & 0.341 & 1.398 \\
\hline & North & 0.041 & 0.546 & 0.305 & 0.975 \\
\hline & South & 0.730 & 0.885 & 0.444 & 1.765 \\
\hline & West & 0.659 & 0.892 & 0.536 & 1.483 \\
\hline \multirow{3}{*}{ Road type } & County & 0.591 & 1 & 1 & 1 \\
\hline & European & 0.951 & 1.022 & 0.520 & 2.008 \\
\hline & District & 0.351 & 0.721 & 0.362 & 1.435 \\
\hline \multirow{3}{*}{ Heavy vehicles } & $<8 \%$ & 0.653 & 0.883 & 0.512 & 1.521 \\
\hline & $8-12 \%$ & 0.838 & 1 & 1 & 1 \\
\hline & $>12 \%$ & 0.783 & 1.075 & 0.644 & 1.792 \\
\hline
\end{tabular}


TABLE 5: Continued.

\begin{tabular}{|c|c|c|c|c|c|}
\hline \multirow[t]{2}{*}{ Parameters } & & \multirow[t]{2}{*}{ Significance } & \multirow[t]{2}{*}{ Odds ratio } & \multicolumn{2}{|c|}{$\begin{array}{l}95.0 \% \text { CI for the } \\
\text { odds ratio }\end{array}$} \\
\hline & & & & Lower & Upper \\
\hline \multirow{11}{*}{ Curve type + High $/$ low + Adjacent curves } & Straight & 0.000 & 1 & 1 & 1 \\
\hline & Single curve + low & 0.013 & 10.739 & 1.653 & 69.754 \\
\hline & Single curve + high & 0.863 & 0.922 & 0.367 & 2.318 \\
\hline & $\begin{array}{l}\text { Multiple opposite dir. } \\
\text { + High + NOT OK }\end{array}$ & 0.000 & 21.993 & 8.465 & 57.141 \\
\hline & $\begin{array}{l}\text { Multiple same dir. } \\
+ \text { High + NOT OK }\end{array}$ & * & $*$ & $*$ & * \\
\hline & $\begin{array}{l}\text { Multiple opposite dir. } \\
\text { + Low + NOT OK }\end{array}$ & 0.000 & 3.341 & 2.010 & 5.552 \\
\hline & $\begin{array}{l}\text { Multiple same dir. } \\
+ \text { Low + NOT OK }\end{array}$ & 0.012 & 2.582 & 1.228 & 5.430 \\
\hline & $\begin{array}{l}\text { Multiple opposite dir. } \\
+ \text { High }+ \text { OK }\end{array}$ & 0.000 & 14.063 & 6.213 & 31.833 \\
\hline & $\begin{array}{c}\text { Multiple same dir. } \\
\text { + High + OK }\end{array}$ & 0.000 & 12.442 & 3.744 & 41.346 \\
\hline & $\begin{array}{l}\text { Multiple opposite dir. } \\
+ \text { Low + OK }\end{array}$ & 0.000 & 4.970 & 2.752 & 8.974 \\
\hline & $\begin{array}{l}\text { Multiple same dir. } \\
+ \text { Low + OK }\end{array}$ & 0.054 & 2.420 & 0.984 & 5.952 \\
\hline
\end{tabular}

* Only one segment had this specific categorization

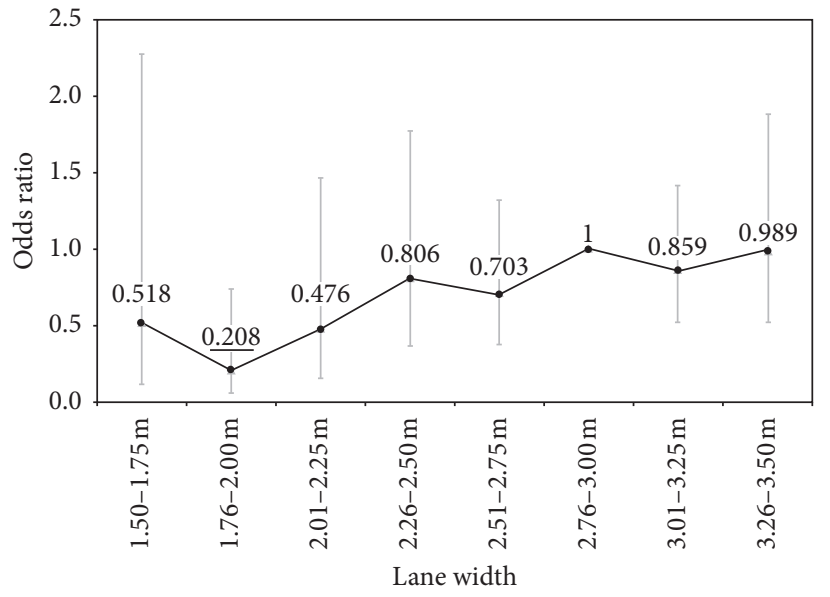

(a)

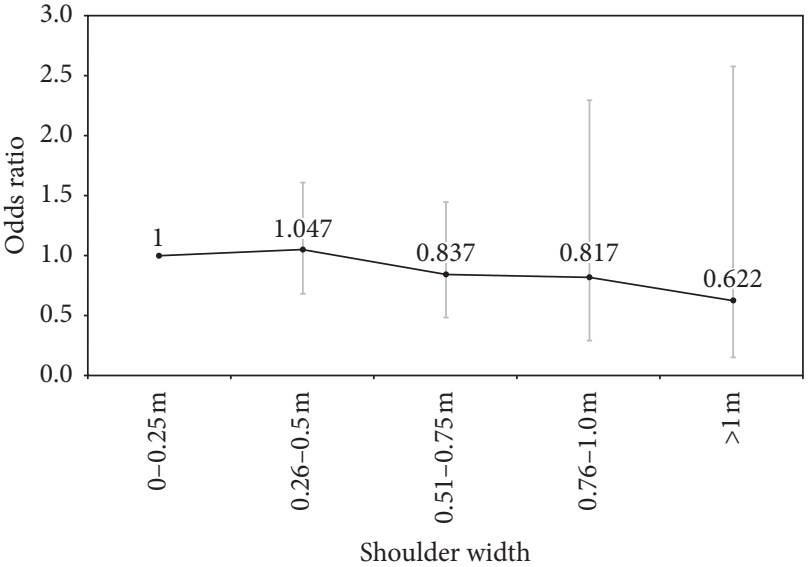

(b)

Figure 2: Odds ratio for (a) lane width and (b) shoulder width and $95 \%$ confidence intervals. Significant $(p<0.05)$ result is underlined.

considerable variation in curve radii). Generally, the odds increase when the curvature is high $(R<200 \mathrm{~m})$ compared to low $(R>200 \mathrm{~m})$. It is clear from the results that curved sections have higher odds ratios compared to straight sections, except for single curved segments with a radius greater than $200 \mathrm{~m}$; however, this result was not significant. As only one segment had the following combination for horizontal alignment, multiple curves in the same direction, with high curvature not fulfilling the requirements for adjacent curves, this was excluded from the results.

6.1. Comparison between Motorcycles and Other Motorized Vehicles. Pokorny et al. [32] conducted a similar study on 1,886 accidents involving motorized vehicles (excluding motorcycles). Nearly, the same baseline was utilized in the current study, making it possible to compare the results with those found in the previous study. The variation between the two studies comes from the way the segmentation is executed and is not believed to impact the comparison. When comparing the odds ratio for shoulder width, the trends are similar for motorcycles and other motorized vehicles, as seen in Figure 4. Increasing shoulder width shows a decreasing odds ratio. The opposite trend appears for traffic lane width, as an increasing lane width shows an increased odds ratio (as seen in Figure 5). This trend appears for both motorcycles and other motorized vehicles. However, for both lane and shoulder width, the $95 \%$ confidence intervals are larger for motorcycles. This could be a consequence of the difference in the sample sizes. The results on lane and shoulder width in the current study show little statistical 


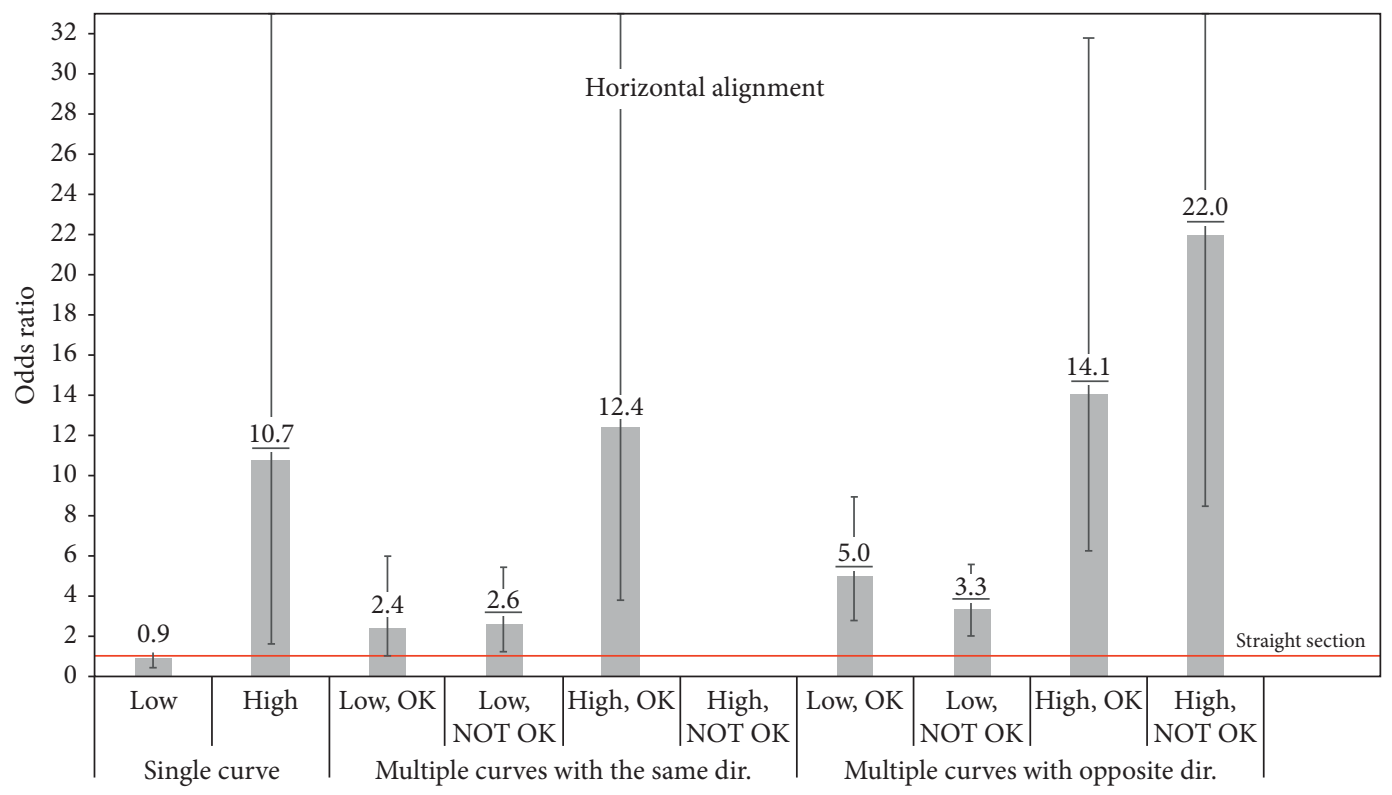

FIGURE 3: Odds ratio for horizontal alignment and $95 \%$ confidence intervals. Significant $(p<0.05)$ results are underlined.

significance, while the results for other motorized vehicles have higher levels of statistical significance, especially for traffic lane width [32].

Pokorny et al. [32] did consider horizontal curvature in their study, but not the requirements for adjacent curves. Therefore, a statistical analysis of the motorcycle accidents, excluding the adjacent curve requirements, was conducted for comparison reasons. Straight sections were used as the baseline in both studies. The results presented in Figure 6 show that the odds ratio for motorcycles is considerably higher than for motorized vehicles, especially when the curvature is high $(R<200 \mathrm{~m})$. Both studies show high levels of statistical significance for the odds ratio on horizontal curvature. However, the $95 \%$ confidence intervals are considerably larger for motorcycles than for motorized vehicles.

\section{Discussion}

The analysis considered the impact of lane width, shoulder width, and various aspects of horizontal curvature on twolane rural roads on the odds risk of single motorcycle accidents.

For lane width, this study shows a trend where increased lane widths are associated with increased odds ratio. The results were statistically significant for only the second narrowest width category $(1.76-2.0 \mathrm{~m})$, which represented only $5.81 \%$ of the total length of the studied road network. The only other relevant motorcycle study found that the width did not significantly impact accident frequency, with the caveat that there was little variation in lane width in the sample, which may have impacted the results [23]. Considering motorized vehicles in general where research is more prevalent, the results of case-control studies vary. While, for example, Gitelman et al. [27] identified a similar trend as found in this study, Gross and Jovanis [29] and Gross and Donnell [28] reported the opposite. Looking

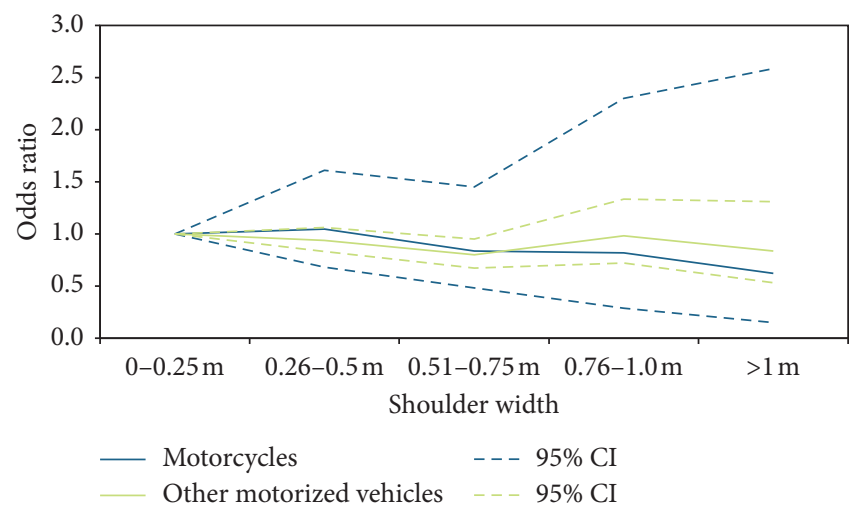

FIgURE 4: Odds ratio for shoulder widths. Motorcycles and other motorized vehicles (including data from [32]).

beyond case-control methodologies, existing research has also provided varying results. Some studies identified wider lanes as safer due to providing more space for avoiding potential collisions [41, 42], while others noted that width has a negative safety effect, where narrower roads might result in safer driving behavior, namely, lower speeds [43]. Thus, the results in the current study might be explained by the motorcyclists taking extra precautions (i.e., reduced speed and increased concentration) when driving on roads with narrow traffic lanes.

Regarding shoulder width, the trend found in this study (increased shoulder width leads to decreased odds for an accident) is similar to other case-control studies [23, 28, 30], although only the first of these studies specifically focused on motorcycles. Again, the results from this study are not statistically significant. The identified trend is interpreted as wider shoulders being beneficial for motorcycle safety because they provide more recovery space and better sight distance in curves. 


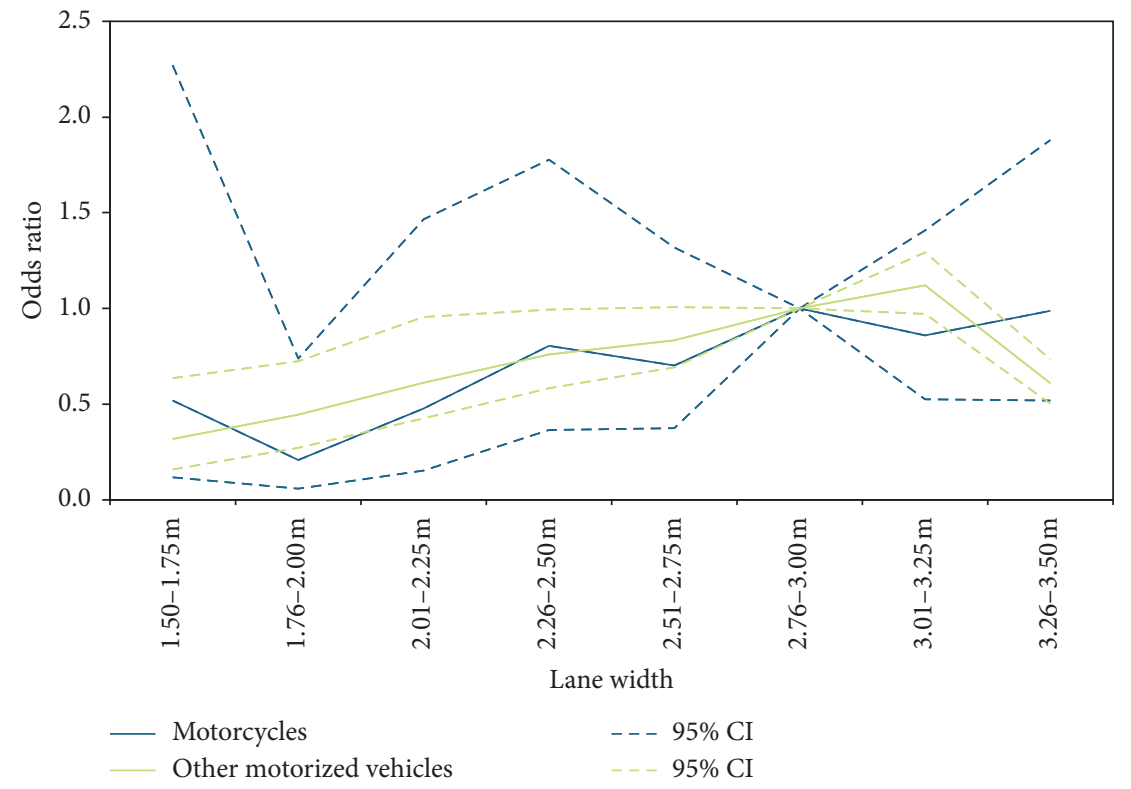

FIgURE 5: Odds ratio for lane widths. Motorcycles and other motorized vehicles (including data from [32]).

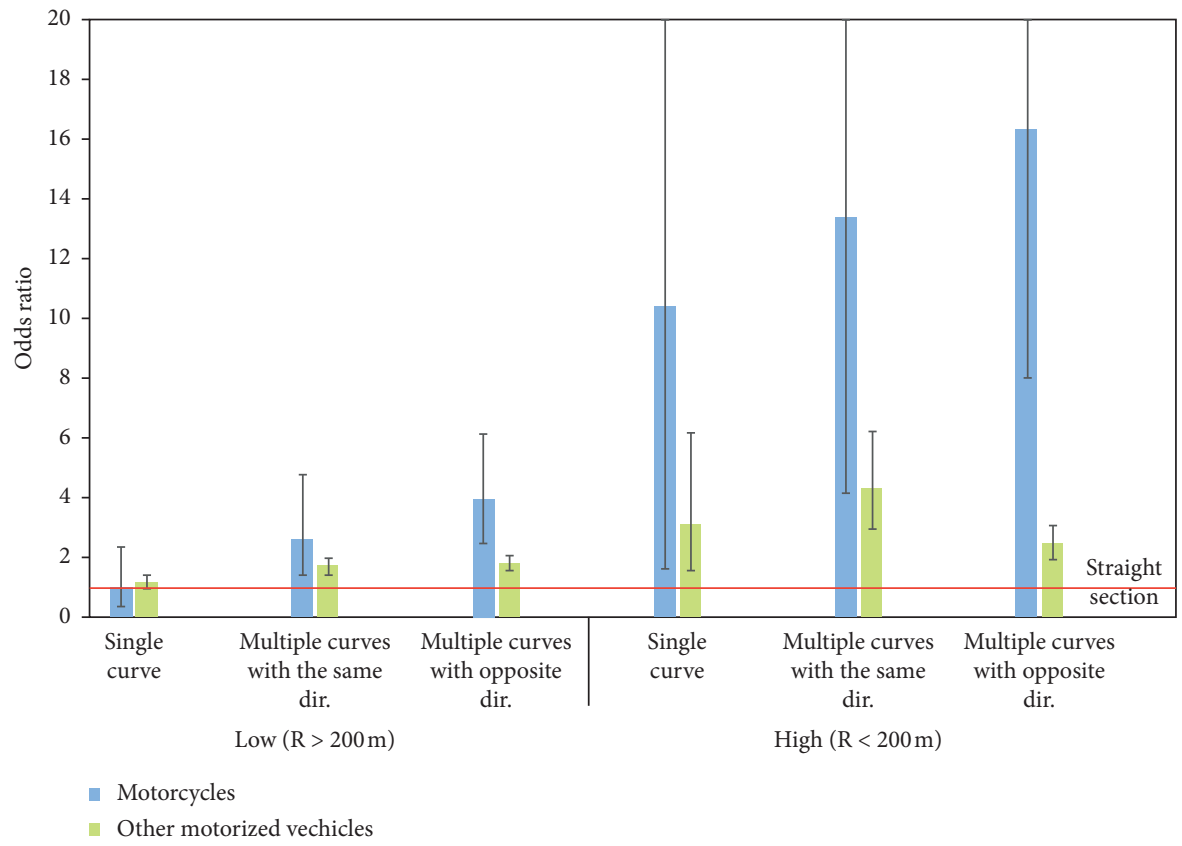

FIGURE 6: Odds ratio for horizontal curvature. Motorcycles and other motorized vehicles (including data from [32]).

Regarding horizontal alignment, the results are more conclusive, showing that the odds ratio is highest on multiple curved segments going in opposite directions (reverse curves). Furthermore, if the segment additionally has high curvature and the requirements for adjacent curves are not fulfilled, the odds ratio increases even further. The odds ratios are lower on segments with low curvature, yet still higher than for straight segments. The results for high curvature are similar to the findings of several studies which are specifically focused on motorcycles [23-25]. However, this is inconsistent with the study by Elvik [22] who found that several sharp curves reduce the risk, although Elvik's study is not specific to motorcycles. While the presence of a reverse curve showed increased odds of an accident, these results differ from other studies focused on motorcycles $[24,25]$ where the presence of a reverse curve is associated with decreased odds for an accident, although using this same dataset Xin [44] later found that reverse curves result in more severe injuries. One reason for the discrepancy compared to this study may be the difference in geography 
associated with the two samples, where Norway has more challenging terrain. The results of this current study related to horizontal alignment are likely explained by the increased complexity by riding a motorcycle in a curve compared to a straight section. Several adjacent curves can make speed adjustment difficult, especially if the radius of the curves varies in size. If the curvature is high, the sight distance around the curve might also be reduced. Another explanation, as stated in the previous research, could also be that such road segments attract risk-seeking riders.

While the results indicate trends such that increased traffic lane widths lead to increased odds for a single motorcycle accident and an opposite effect for increased shoulder widths, these results are not largely statistically significant. The results on horizontal alignment show higher statistical significance for most of the categories, compared to the results on lane and shoulder width. These results indicate that the horizontal alignment has a greater influence on single motorcycle accidents than lane and shoulder width or that lane and shoulder width do not influence single motorcycle accidents at all. The results from the study by Pokorny et al. [32] involving motorized vehicles also show less significance for shoulder width compared to traffic lane width and horizontal alignment. This strengthens the indication that shoulder width has less influence on accidents compared to the other design parameters studied. However, the lack of statistical significance and large confidence intervals could also be affected by a low sample size (i.e., low number of accidents). Possible ways to increase the sample size would be to either extend the study period or include more accident types. Including more accident types would lead to a broad definition of cases, which could lead to unclear results, and thus is not suggested [33]. Increasing the study period could lead to temporal variations within the data, which would not be favorable either. However, a greater sample size may not solve these issues in their entirety, as the sample size in the study by Pokorny et al. [32] was ten times greater than in the current study and yet several of the results were insignificant. Additionally, the comparison between the two studies shows that horizontal curvature is more influential on accident risk for motorcycles than for other motorized vehicles.

Increasing the knowledge on risk factors related to motorcycle accidents can help reduce the number of accidents. Based on this study, the importance of horizontal curve design is emphasized for motorcycle safety. When considering motorcycle safety for future road facilities, larger curve radii are preferred along with single curves. It is also important that the requirements for adjacent curves are fulfilled.

\section{Data Availability}

The data included in this study are available upon request by contact with the corresponding author.

\section{Conflicts of Interest}

The authors declare that there are no conflicts of interest.

\section{References}

[1] 2019 The Norwegian Public Roads Administration. https:// www.vegvesen.no/fag/fokusomrader/trafikksikkerhet/ nullvisjonen.

[2] S. Norway, Road traffic accidents involving personal injury https://www.ssb.no/en/transport-og-reiseliv/statistikker/vtu/ aar, 2021.

[3] T. Bjørnskau, Road Traffic Risk in Norway Transportøkonomisk institutt, 2015.

[4] M. D. Keall and S. Newstead, "Analysis of factors that increase motorcycle rider risk compared to car driver risk," Accident Analysis \& Prevention, vol. 49, pp. 23-29, 2012.

[5] P. A. Turner and N. Georggi, "Analysis of alcohol-related motorcycle crashes in Florida and recommended countermeasures," Journal of the Transportation Research Board, vol. 1779, no. 1, pp. 189-196, 2001.

[6] A. Maistros, W. H. Schneider, and P. T. Savolainen, "A comparison of contributing factors between alcohol related single vehicle motorcycle and car crashes," Journal of Safety Research, vol. 49, pp. e1-135, 2014.

[7] A. Moskal, J.-L. Martin, and B. Laumon, "Risk factors for injury accidents among moped and motorcycle riders," Accident Analysis \& Prevention, vol. 49, pp. 5-11, 2012.

[8] B. Wali, A. J. Khattak, and A. J. Khattak, "A heterogeneity based case-control analysis of motorcyclist's injury crashes: evidence from motorcycle crash causation study," Accident Analysis \& Prevention, vol. 119, pp. 202-214, 2018.

[9] W. H. Schneider, P. T. Savolainen, D. Van Boxel, and R. Beverley, "Examination of factors determining fault in twovehicle motorcycle crashes," Accident Analysis \& Prevention, vol. 45, pp. 669-676, 2012.

[10] D. Eustace, V. K. Indupuru, and P. Hovey, "Identification of risk factors associated with motorcycle-related fatalities in Ohio," Journal of Transportation Engineering, vol. 137, no. 7, pp. 474-480, 2011.

[11] E. I. Vlahogianni, G. Yannis, and J. C. Golias, "Overview of critical risk factors in Power-Two-Wheeler safety," Accident Analysis \& Prevention, vol. 49, pp. 12-22, 2012.

[12] H. Hurt, J. Ouellet, and D. Thom, "Motorcycle accident cause factors and identification of countermeasures," National Highway Traffic Safety Administration, vol. 91, pp. 200-207, 1981.

[13] D. F. Preusser, A. F. Williams, and R. G. Ulmer, "Analysis of fatal motorcycle crashes: crash typing," Accident Analysis \& Prevention, vol. 27, no. 6, pp. 845-851, 1995.

[14] D. D. Clarke, P. Ward, C. Bartle, and W. Truman, "The role of motorcyclist and other driver behaviour in two types of serious accident in the UK," Accident Analysis \& Prevention, vol. 39, no. 5, pp. 974-981, 2007.

[15] T. Flask, W. H. Schneider, and D. Lord, "A segment level analysis of multi-vehicle motorcycle crashes in Ohio using Bayesian multi-level mixed effects models," Safety Science, vol. 66, pp. 47-53, 2014.

[16] A. Montella, R. de Oña, F. Mauriello, M. Rella Riccardi, and G. Silvestro, "A data mining approach to investigate patterns of powered two-wheeler crashes in Spain," Accident Analysis \& Prevention, vol. 134, Article ID 105251, 2020.

[17] A. Høye, T. Vaa, and S. I. Hesjevoll, Temaanalyse Av Dødsulykker På Motorsykkel 2005-2014 Transportøkonomisk Institutt, 2016.

[18] R. Elvik, "Can evolutionary theory explain the slow development of knowledge about the level of safety built into 
roads?” Accident Analysis \& Prevention, vol. 106, pp. 166-172, 2017.

[19] C. W. Yuen, M. R. Karim, and A. Saifizul, "Investigation on motorcyclist riding behaviour at curve entry using instrumented motorcycle," The Scientific World Journal, vol. 2014, Article ID 968946, 9 pages, 2014.

[20] M. K. A. Ibrahim, H. Hamid, T. H. Law, and S. V. Wong, "Evaluating the effect of lane width and roadside configurations on speed, lateral position and likelihood of comfortable overtaking in exclusive motorcycle lane," Accident Analysis \& Prevention, vol. 111, pp. 63-70, 2018.

[21] R. Elvik, "International transferability of accident modification functions for horizontal curves," Accident Analysis \& Prevention, vol. 59, p. 487, 2013.

[22] R. Elvik, "The more (sharp) curves, the lower the risk," Accident Analysis \& Prevention, vol. 133, Article ID 105322, 2019.

[23] W. H. Schneider, P. T. Savolainen, and D. N. Moore, "Effects of horizontal curvature on single-vehicle motorcycle crashes along rural two-lane highways," Transportation Research Record: Journal of the Transportation Research Board, vol. 2194, no. 1, pp. 91-98, 2010.

[24] C. Xin, Z. Wang, P.-S. Lin, C. Lee, and R. Guo, "Safety effects of horizontal curve design on motorcycle crash frequency on rural, two-lane, undivided highways in Florida," Transportation Research Record: Journal of the Transportation Research Board, vol. 2637, no. 1, pp. 1-8, 2017.

[25] C. Xin, Z. Wang, C. Lee et al., "Development of crash modification factors of horizontal curve design features for single-motorcycle crashes on rural two-lane highways: a matched case-control study," Accident Analysis \& Prevention, vol. 123, pp. 51-59, 2019.

[26] A. Høye, R. Elvik, T. Vaa, and M. Sorensen, Trafikksikkerhetshåndboken, Oslo: Transportøkonomisk institutt, 2012.

[27] V. Gitelman, E. Doveh, R. Carmel, and S. Hakkert, "The influence of shoulder characteristics on the safety level of twolane roads: a case-study," Accident Analysis \& Prevention, vol. 122, pp. 108-118, 2019.

[28] F. Gross and E. T. Donnell, "Case-control and cross-sectional methods for estimating crash modification factors: comparisons from roadway lighting and lane and shoulder width safety effect studies," Journal of Safety Research, vol. 42, no. 2, p. 117, 2011.

[29] F. Gross and P. P. Jovanis, "Estimation of the safety effectiveness of lane and shoulder width: case-control approach," Journal of Transportation Engineering, vol. 133, no. 6, pp. 362-369, 2007.

[30] F. Gross, P. P. Jovanis, and K. Eccles, "Safety effectiveness of lane and shoulder width combinations on rural, two-lane, undivided roads," Transportation Research Record: Journal of the Transportation Research Board, vol. 2103, no. 1, pp. 42-49, 2009.

[31] C. Zegeer, R. Deen, and J. Mayes, The Effect of Lane and Shoulder Widths on Accident Reductions on Rural, Two-Lane Roads, University of Kentucky, Lexington, Kentucky, 1980.

[32] P. Pokorny, J. Jensen, K. Pitera, and F. Gross, "Safety effects of traffic lane and shoulder widths on two-lane undivided rural roads: a matched case-control study from Norway," Accident Analysis and Prevention, vol. 144, Article ID 105614, 2020.

[33] F. Gross, B. Persaud, and C. Lyon, A guide to developing quality crash modification factors Office of Safety, 2010.
[34] F. Gross, "Case-control analysis in highway safety: accounting for sites with multiple crashes," Accident Analysis \& Prevention, vol. 61, pp. 87-96, 2013.

[35] J. L. Marsh, J. L. Hutton, and K. Binks, "Removal of radiation dose response effects: an example of over-matching," $B m j$, vol. 325, no. 7359, p. 327, 2002.

[36] The Norwegian Public Roads Administration, Håndbok N100 Veg- Og Gateutforming https://www.vegvesen.no/_ attachment $/ 61414 /$ binary $/ 1355470$ ?fast_title $=\mathrm{H} \% \mathrm{C} 3 \%$ A5ndbok+N100+Veg-+og+gateutforming+\%286+MB\%29. pdf, 2019.

[37] The Norwegian Public Roads Administration, Håndbok V120 Premisser for geometrisk utforming av veger 2019.https://www. vegvesen.no/_attachment/61500/binary/1327507?fast_title $=\mathrm{H}$ $\% \mathrm{C} 3 \% \mathrm{~A} 5$ ndbok+V120+Premisser+for +geometrisk+utforming+av+veger.pdf., 2019.

[38] V. Jevtić, M. Vujanić, K. Lipovac, D. Jovanović, and D. Pešić, "The relationship between the travelling speed and motorcycle styles in urban settings: a case study in Belgrade," Accident Analysis and Prevention, vol. 75, pp. 77-85, 2015.

[39] P. Jovanis and F. Gross, "Estimation of safety effectiveness of changes in shoulder width with case control and cohort methods," Transportation Research Record, vol. 2019, pp. 237-245, 2007.

[40] The Norwegian Public Roads Administration, Produktspesifikasjon: NVDB Trafikkulykker http://sosi.geonorge.no/ Produktspesifikasjoner/Produktspesifikasjon_SVV_ Trafikkulykke_20180315.pdf, 2020.

[41] C. Zeeger and J. Deacon, Effect of Lane Width, Shoulder Width, and Shoulder Type on Highway Safety http:// onlinepubs.trb.org/Onlinepubs/state-of-the-art/6/6-001.pdf, 1987.

[42] C. Zegeer, R. Stewart, and F. Neuman, "Accident relationships ofroadwaywidth onlow-volume roads," Translational Research, vol. 160, no. 1, pp. 45-64, 1994.

[43] J. Milton and F. Mannering, "The relationship among highway geometrics, traffic-related elements and motor-vehicle accident frequencies," Transportation, vol. 25, no. 4, pp. 395-413, 1998.

[44] C. Xin, Z. Wang, C. Lee, and P.-S. Lin, "Modeling safety effects of horizontal curve design on injury severity of single-motorcycle crashes with mixed-effects logistic model," Transportation Research Record: Journal of the Transportation Research Board, vol. 2637, no. 1, pp. 38-46, 2017. 